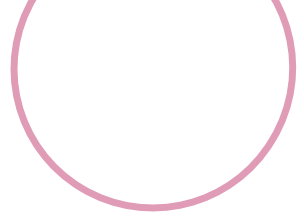

\title{
Avaliação da usabilidade do site da Biblioteca Pública do Estado de Santa Catarina
}

Usability evaluation of the Santa Catarina Public Library website

\author{
Daniela Capri \\ Universidade do Vale do Itajai \\ dccapri@gmail.com $\mathbf{x}$
}

Giorgio Gilwan da Silva

Universidade do Vale do Itajai

giorgiogilwan@univali.br $\boldsymbol{x}$

$\sum_{\frac{1}{n}}^{\frac{1}{n}}$

\section{PROJE'TICA}

\section{COMO CITAR ESTE ARTIGO:}

CAPRI, Daniela; SILVA, Giorgio Gilwan da. Avaliação da usabilidade do site da Biblioteca Pública do Estado de Santa Catarina. Projética, Londrina, v. 12, n. 1, p. $168-194,2021$

DOI: 10.5433/2236-2207.2021v12n1p168

Submissão: 12-07-2019

Aceite: 11-11-2019 
RESUMO: Este trabalho tem como objetivo analisar a usabilidade do site da Biblioteca Pública de Santa Catarina (BPSC). Para este fim, a pesquisa foi dividida em três etapas: avaliação heurística; teste de usabilidade e comparativo entre a avaliação heurística e o teste de usabilidade. Os resultados obtidos apontaram uma deficiência na usabilidade do site da BPSC o que dificulta sua utilização e pode acabar afastando os usuários.

Palavras-chave: Usabilidade. Heurísticas de Nielsen. Usabilidade de sites. Biblioteca Pública de Santa Catarina.

ABSTRACT: This paper aims to analyze the usability of the Santa Catarina Public Library website. To do so, the research was divided in three stages: the heuristic evaluation, the usability test and the comparison between heuristic evaluation and usability test. Results show a deficiency in the usability of the library website, which makes its use difficult and may end up driving users away.

Keywords: Usability. Nielsen Heuristics. Website usability. Santa Catarina Public Library.

\section{INTRODUÇÃO}

De acordo com o (SNBP) Sistema Nacional de Bibliotecas Públicas (2018) as bibliotecas públicas têm por objetivo "atender por meio do seu acervo e de seus serviços os diferentes interesses de leitura e informação da comunidade em que está localizada, colaborando para ampliar o acesso à informação, à leitura e ao 
livro, de forma gratuita". Com o crescimento do mundo virtual, é essencial para a evolução das bibliotecas e sua inclusão neste novo contexto, oferecer seus serviços de forma online, por exemplo, por meio de websites, buscando assim atingir um público maior e cumprir de forma mais abrangente seus objetivos.

De acordo com Bax (1998), a inserção das bibliotecas na web é fundamental, pois lentamente vai estabelecendo uma mudança radical na maneira de servir seu público, o autor afirma ainda que as bibliotecas que não se adaptarem às mudanças e não forem capazes de se inserir no mundo virtual de forma efetiva e eficaz desaparecerão ao longo do tempo por falta de usuários. No entanto, a simples inserção das bibliotecas na internet através de web sites não é o suficiente, é imprescindível que estes portais sejam acessíveis, e eficientes para que cumpram com seu papel. Brinkley (1999, p. 8-15) comenta que o "web site é o melhor meio para promover e publicar os serviços oferecidos pela biblioteca." Contudo, se o site não for eficaz, os serviços não chegarão aos usuários e de nada adiantará manter o site.

De acordo com pesquisas feitas pelo Instituto Pró Livro (2016) e Instituto Brasileiro de Geografia e Estatística (IBGE, 2017) o Brasil possui 207,7 milhões de habitantes sendo que $44 \%$ desta população é considerada não leitora. Um dos fatores que elevam o número de não leitores no país é a dificuldade de acesso às bibliotecas. Existem atualmente, 6.012 bibliotecas públicas distribuídas nos 26 estados brasileiros (cerca de uma biblioteca a cada 34.500 pessoas).

O estado de Santa Catarina possui 6.248.436 habitantes e 225 Bibliotecas Públicas (1 biblioteca a cada 27.770 habitante) (SISTEMA NACIONAL DE BIBLIOTECAS PÚBLICAS, 2018). Buscando facilitar o acesso da população às bibliotecas públicas, estas têm buscado inserir-se no mundo digital através de sites e catálogos online. No entanto, o público atendido por uma biblioteca pública é muito amplo, "atende a todos os públicos, bebês, crianças, jovens, adultos, pessoas da melhor idade e 
pessoas com deficiência" (SISTEMA NACIONAL DE BIBLIOTECAS PÚBLICAS, 2018) de todas as classes sociais e níveis de escolaridade.

Para isso é fundamental refletir sobre questões de desenvolvimento e qualidade destes sites onde estão disponibilizados os produtos e serviços, pois caso não atendam satisfatoriamente ao público, este podem perder o interesse e muitas vezes até mesmo abandonar o sistema. Portanto, a usabilidade dos websites de bibliotecas precisa ser avaliada, pois é um fator determinante para a satisfação dos usuários.

A partir deste cenário, elaborou-se a seguinte pergunta de pesquisa: o site da Biblioteca Pública do Estado de Santa Catarina, é claro, de fácil entendimento e utilização?

Buscando responder à questão de pesquisa foi traçado o seguinte objetivo geral: Analisar a usabilidade do site da biblioteca pública do Estado de Santa Catarina comparando a análise heurística com os resultados do teste de usabilidade, e para atingi-lo foram necessárias as seguintes etapas: análise heurística do site da Biblioteca Pública de Santa Catarina; teste de usabilidade com usuários; comparação da análise heurística e dos resultados do teste de usabilidade.

\section{BIBLIOTECAS PÚBLICAS}

A primeira Biblioteca Pública fundada no Brasil, foi a Biblioteca Pública da Bahia, no ano de 1811 pela iniciativa de um senhor de engenho, Pedro Ferrão de Castelo Branco. Foi idealizada por seus criadores, para servir de local e instrumento de instrução popular, porém, seu público se restringia a leitores que dominavam um segundo idioma e provocava sentimento de exclusão e ignorância à população analfabeta (grande maioria da população), estereotipando a biblioteca como um 
"templo do saber". Após a criação da primeira biblioteca pública, o governo inicia a criação de várias bibliotecas públicas nos Estados, porém, essas instituições eram improvisadas, seu acervo desatualizado e com poucos recursos humanos, causando ao povo, uma imagem negativa, de um local para poucos, para uma elite de eruditos. A partir da década de 1930, as bibliotecas públicas cresceram e se multiplicaram pelo país. Este fato deve-se, sobretudo, à criação do Instituto Nacional do Livro - INL, em 1937 e em 1992 do Sistema Nacional de Bibliotecas Públicas (SNBP). Porém, mesmo com o trabalho de universalização das bibliotecas públicas, o estereótipo de biblioteca para poucos, e templo do saber ainda é muito presente na cabeça do povo brasileiro. (OLIVEIRA, 1994; SISTEMA NACIONAL DE BIBLIOTECAS PÚBLICAS, 2018; SUAIDEN, 1980).

Em contraponto desta visão de biblioteca para poucos, a Biblioteca Pública deve buscar desempenhar seu papel no desenvolvimento e manutenção de uma sociedade democrática, oferecendo aos indivíduos acesso a ideias e opiniões diversas, contribuindo para a ampliação do conhecimento. O principal objetivo da biblioteca pública é "fornecer recursos e serviços em diversos suportes, de modo a ir ao encontro das necessidades individuais ou coletivas, no domínio da educação, informação e desenvolvimento pessoal, e também de recreação e lazer." (KOONTZ; GUBBIN, 2013).

Em um levantamento realizado por Blattmann, Fragoso e Viapiana (2006), entre as 27 (vinte e sete) bibliotecas públicas estaduais brasileiras, como resultado, constatou-se: 19 (dezenove) bibliotecas com presença em site. Já no ano de 2013 em novo levantamento, 21 bibliotecas apresentavam site ou blog. Na região sul, as bibliotecas dos três estados (Rio Grande do Sul, Santa Catarina e Paraná) apresentam site para se aproximar de seu público (SALGADO; MODESTO, 2013). 


\subsection{Biblioteca Públicas de Santa Catarina}

Com a Resolução n 373, em 31 de maio de 1854 (COUTINHO; PEREIRA; CARDOZO, 1854), João José Coutinho, então presidente da província, cria a Biblioteca Pública do Estado de Santa Catarina, mas, sua inauguração ocorre apenas em 9 de janeiro de 1855. O prédio atual da biblioteca está localizado na área central de Florianópolis, capital catarinense.

A biblioteca apresenta como missão manter, conservar e disponibilizar parte da memória cultural do Estado para a população catarinense e promover o hábito da leitura. Seu acervo é composto por títulos de diversas áreas do conhecimento, em suportes variados, além de uma coleção de periódicos e uma de obras raras. Funciona também como Depósito Legal através da Lei n 11.074, de 11 de janeiro, que dispões sobre a obrigatoriedade de editoras e escritores catarinenses realizarem a doação de um exemplar de cada obra impressa para o seu acervo (SANTA CATARINA, 1999).

Para melhor atender a comunidade, alguns serviços são disponibilizados pela BPSC, como a consulta local (consulta no próprio ambiente da Biblioteca); o Mural Livre (espaço aberto para divulgação de trabalhos gráficos, poéticos e notícias gerais); o Laboratório de Conservação, Restauração e Encadernação da biblioteca - LACRE (serviço interno com o objetivo de recuperar os livros danificados do acervo); a Oficina Literária Boca de Leão (tem como objetivo iniciar os participantes no processo de escrita para a liberação da criatividade textual; conhecer gêneros literários; estudar clássicos da literatura nacional e estrangeira; estudar contos; escrever contos curtos; e escrever um conto para compor o e-book anual da Oficina). Já no ambiente digital, por meio de seu site, a biblioteca disponibiliza seu catálogo de obras para consultas online, conta também com a Hemeroteca digital 
catarinense (que tem por objetivo divulgar o acervo documental de publicações periódicas, em especial jornais editados e publicados em Santa Catarina a partir do século XIX).

\section{INTERAÇÃO HUMANO COMPUTADOR - IHC}

Interação Humano Computador - IHC é o estudo da interação entre pessoas e computadores, que acontece por meio de uma interface. Durante a utilização de uma interface não deve ser necessário o conhecimento de seu funcionamento, o usuário não deve precisar pensar em sua estruturação ou idealização, é fundamental que os elementos que têm efeito sobre o usuário estejam disponíveis e de fácil entendimento. De acordo com Brenda Laurel (1990) uma boa interface é aquela que leva o usuário a ter mais poder e ser mais independente.

Rocha e Baranauskas (2003, p. 14) definem IHC como uma "disciplina preocupada com o design, avaliação e implementação de sistemas computacionais interativos para uso humano e com o estudo dos principais fenômenos ao redor deles", complementando ainda que "IHC trata do design de sistemas computacionais que auxiliem as pessoas de forma a que possam executar suas atividades produtivamente e com segurança". A partir desta visão serão estudados os conceitos de usabilidade na web, testes de usabilidade e heurísticas.

\subsection{Usabilidade na Web}

De acordo com a ISO 92-41-11 usabilidade é um indicador de qualidade que mede a facilidade de utilização de um sistewma, produto ou serviço em um contexto específico de uso, para atingir objetivos específicos, por usuários específicos com eficácia, eficiência e satisfação. Onde a eficácia é normalmente medida quando o sistema possibilita que o usuário atinja seus objetivos; a eficiência pelo tempo de resposta, tempo total para desenvolver a tarefa e número de erros e a satisfação considera os sentimentos, percepções e opiniões do usuário (DIAS, 2007). 
Avaliação da usabilidade do site... Santa Catarina CAPRI, D.; SILVA G. G. da

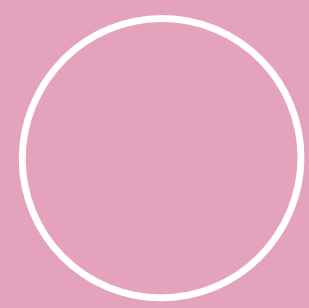

De acordo com a ISO 92-41-11 usabilidade é um indicador de qualidade que mede a facilidade de utilização de um sistema, produto ou serviço em um contexto específico de uso, para atingir objetivos específicos, por usuários específicos com eficácia, eficiência e satisfação.

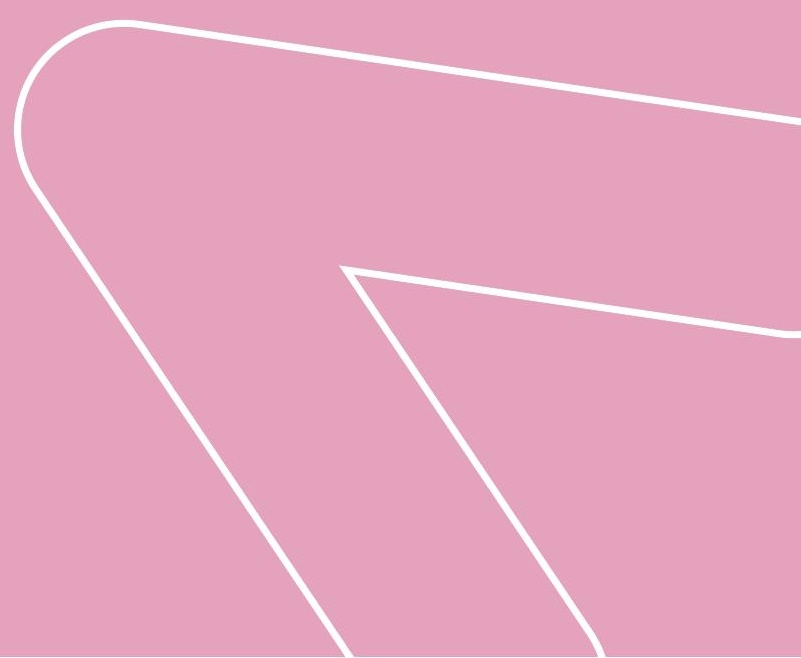


Sharp, Rogers e Preece (2007) buscam ampliar o conceito da norma e apresentam duas categorias de atributos de usabilidade a serem observados: no aspecto da qualidade, deve-se levar em consideração a efetividade, segurança, utilidade, facilidade de lembrança, facilidade de aprendizagem, eficiência. Já nos aspectos afetivos, são apresentados atributos como diversão, satisfação, entretenimento, prestatividade, motivação, estética e o quanto as pessoas gostam de usar o sistema. Em uma análise de usabilidade é importante levar em consideração além dos atributos apresentados na norma, os atributos de qualidade e afetivos, pois se as pessoas não puderem ou não utilizarem um recurso, ele pode não mais existir (NIELSEN; LORANGER, 2007).

No contexto da web a usabilidade é uma característica muito importante, pois com o grande número de páginas disponíveis na internet, caso ao visitar uma delas, o usuário não descubra rapidamente como utilizá-la ou não encontre a informação necessária ele logo irá buscar outra mais acessível. A usabilidade dos sites é experimentada antes da decisão de utilizá-lo ou não, neste sentido a usabilidade é de vital importância para a existência e manutenção na web (NIELSEN, 2000a).

\subsection{Avaliação de Usabilidade}

Para avaliar se um site tem boa usabilidade, melhorando assim sua chance de ser acessado e fidelizar o usuário, existe a avaliação de usabilidade, que mede os problemas de usabilidade de um sistema. Estes problemas são geralmente divididos como: uma barreira, um obstáculo ou um ruído, dependendo o quanto afetam a interação do usuário com o sistema. Um problema é considerado uma barreira quando mesmo se deparando com ele frequentemente, o usuário não consegue solucioná-lo sem auxílio; classifica-se como obstáculo quando o usuário encontra uma dificuldade, mas consegue resolvê-la sem ajuda depois de algumas tentativas e são chamados de ruído as dificuldades mais brandas, que logo o usuário consegue resolver (CYBIS, 2003). 
Para identificar e classificar estes problemas, existem técnicas de avaliação de usabilidade, divididas em três grupos, são elas, as Técnicas Prospectivas (testes com usuários), buscam a opinião do usuário sobre a interação com o sistema; Técnicas Preditivas ou Diagnósticas (inspeção), buscam prever os erros de projeto de interfaces sem a participação direta de usuários e Técnicas Objetivas ou Empíricas (baseado em modelos), buscam constatar os problemas a partir da observação do usuário interagindo com o sistema (CYBIS, 2003; DIAS, 2007).

Para realização classificar e identificar os problemas neste trabalho serão utilizadas técnicas prospectivas, teste com usuários, e técnicas preditivas, avaliação heurística.

\subsection{Heurísticas}

A avaliação heurística é uma técnica prospectiva, baseada em guias de recomendações e guias de estilos, que servem como princípios e diretrizes (heurísticas), visando encontrar problemas a serem corrigidos e aplicar melhorias de usabilidade. Esta metodologia foi desenvolvida como uma alternativa para minimizar custos ao realizar inspeções de software (NIELSEN, 1994).

Na década de 90, Nielsen com o auxílio de Molich, desenvolveram 10 heurísticas para avaliar usabilidade a partir de fatores observado em um conjunto de problemas de usabilidade detectados em estudos empíricos. Abaixo são listadas as 10 diretrizes desenvolvidas, conhecidas como heurísticas de Nielsen (1994):

1) visibilidade do estado atual do sistema;

2) correlação entre o sistema e o mundo real;

3) controle e liberdade do usuário;

4) consistência e padrões;

5) prevenção de erros; 
6) reconhecimento ao invés de memorização;

7) flexibilidade e eficiência de uso;

8) projeto estético e minimalista;

9) suporte aos usuários no reconhecimento, diagnóstico e recuperação de erros;

10) informações de ajuda e documentação.

Ao realizar uma avaliação heurística é indicada que se estabeleça um bom plano de trabalho, pois, existe a possibilidade da produção de diagnósticos e sugestões de revisão equivocadas. Sugere-se para montagem do plano de trabalho, iniciar pela análise do contexto da avaliação, onde são identificados os recursos disponíveis e os objetivos da avaliação; em seguida, é definida a estratégia de avaliação, a partir da montagem do time de avaliadores, análise do contexto de operação do sistema e do conhecimento disponível, conversa com usuários sobre modo de utilização, preparativos para a avaliação; após definidos e estabelecidas estas etapas, é executada a avaliação; e a última etapa é redação do relatório de avaliação e reunião de apresentação do relatório, onde ficarão registrados os problemas identificados e as propostas de soluções sugeridas (CYBIS, 2003; CYBIS; BETIOL; FAUST, 2015).

\section{METODOLOGIA}

Quanto aos objetivos, a pesquisa pode ser classificada como exploratória, que de acordo com Gil (2007) objetiva proporcionar maior familiaridade com o problema, buscando torná-lo mais explícito ou construir hipóteses. Para isto, foi realizado levantamento do que já havia publicado sobre o assunto na internet, em bases de dados, periódicos científicos e livros. A pesquisa caracteriza-se também como bibliográfica, que de acordo com Fonseca (2002, p. 32) é feita por meio do levantamento de referências já analisadas e de publicações tanto impressas quanto digitais, como livros, publicações de periódicos científicos, páginas de web sites. 
Para avaliação da usabilidade do site, serão realizadas três etapas: avaliação heurística; teste de usabilidade e comparativo entre a avaliação heurística e o teste de usabilidade.

Avaliação do website: método de avaliação heurística a ser desenvolvida em três etapas, conforme (SILVA; BARBOSA, 2010):

a) Preparação: definição e organização das telas que serão avaliadas e a lista de heurísticas a serem utilizadas;

b) Coleta de Dados e Interpretação (avaliação): inspeção da interface para identificar violações das heurísticas; listar os problemas encontrados pela inspeção, indicando local, gravidade, justificativa e recomendação.

c) Consolidação dos resultados e Relato dos resultados: revisão dos problemas encontrados, elencando a relevância, gravidade, justificativa e recomendação de solução; gerar relatório consolidados da avaliação.

Teste de usabilidade com usuários: será elaborada uma persona baseada nos usuários reais da biblioteca e o teste será realizado com 5 pessoas com o perfil selecionado, pois de acordo com Nielsen (2000b) “após o quinto usuário, você está perdendo seu tempo observando os mesmos problemas e aprendendo muito pouca coisa nova". O teste será realizado em computador, baseado em um roteiro de atividades. Será realizada observação do usuário por dois observadores, um conduzirá a pesquisa e outro realizará as anotações e observações do usuário. Os dados serão computados em planilhas para posterior comparação com resultado da análise heurística. Os dados serão tratados e os resultado apresentados por meio de planilhas, quadros e gráficos e caso necessário, sugestões de novas telas para o website. 


\section{RESULTADOS E DISCUSSÃO}

\subsection{Análise Heurística do Site da Biblioteca Pública de Santa Catarina}

A análise heurística do site da Biblioteca Pública de Santa Catarina foi realizada em duas etapas: primeiro a análise do site da Fundação Catarinense de Cultura - onde estão hospedadas as páginas da biblioteca - e em seguida foi realizada a análise do site Sábio - utilizado para pesquisa e outras ações relacionadas ao acervo da biblioteca.

Para definir a gravidade dos problemas encontrados utilizou-se uma escala de 0 a 4, onde, 0 - Não é encarado necessariamente como um problema de usabilidade; 1 - Problema estético que não tem necessidade de ser corrigido, a menos que haja tempo e recurso disponível; 2 - Pequeno problema com baixa prioridade na correção; 3 - Problema com alta prioridade de correção e 4 - Problema que afeta a utilização do site e deve ser corrigido. No registro dos problemas encontrados foi utilizado um quadro onde é identificada a Heurística violada, qual o erra encontrado, o local em que o erro é apresentado, a gravidade (de acordo com a escala apresentada) e uma sugestão de solução.

No quadro 1, é exposta a análise heurística do Site da Biblioteca Pública:

Quadro 1 - Análise heurística do Site da BPSC

\begin{tabular}{|l|l|c|c|c|}
\hline \multicolumn{5}{|c|}{ Site da Biblioteca Pública } \\
\hline \multicolumn{1}{|c|}{ Heurística Violada } & \multicolumn{1}{|c|}{ Erro } & Local & Gravidade & \multicolumn{1}{c|}{ Solução } \\
\hline $\begin{array}{l}\text { Reconhecimento e } \\
\text { não memorização }\end{array}$ & $\begin{array}{l}\text { São apresentados alguns serviços } \\
\text { mas não há indicação que se for } \\
\text { clicado no nome do serviço irão } \\
\text { aparecer outros serviços, entende-se } \\
\text { que são apenas os que aparecem na } \\
\text { tela inicial. }\end{array}$ & $\begin{array}{l}\text { No item } \\
\text { Serviços }\end{array}$ & 3 & $\begin{array}{l}\text { Criar uma } \\
\text { mensagem de para } \\
\text { saber mais clique } \\
\text { aqui ao final dos } \\
\text { textos }\end{array}$ \\
\hline $\begin{array}{l}\text { Controle e liberdade } \\
\text { do usuário }\end{array}$ & $\begin{array}{l}\text { Quando é selecionado um dos item } \\
\text { de Acervo não existe a opção voltar }\end{array}$ & $\begin{array}{l}\text { No item } \\
\text { acervo }\end{array}$ & 2 & $\begin{array}{l}\text { Criar um ícone } \\
\text { voltar após o texto }\end{array}$ \\
\hline $\begin{array}{l}\text { Consistência e } \\
\text { padrões }\end{array}$ & $\begin{array}{l}\text { A palavra serviços é utilizada em dois } \\
\text { contextos diferentes }\end{array}$ & $\begin{array}{l}\text { No item } \\
\text { serviços }\end{array}$ & 2 & $\begin{array}{l}\text { Todos os serviços } \\
\text { serem listados em } \\
\text { uma tabela como é } \\
\text { feito no item } \\
\text { acervo }\end{array}$ \\
\hline
\end{tabular}




\begin{tabular}{|l|l|l|c|l|}
\hline $\begin{array}{l}\text { Consistência e } \\
\text { padrões }\end{array}$ & $\begin{array}{l}\text { A apresentação de itens (links) é } \\
\text { utilizada de três formas diferentes: } \\
\text { no item serviços em forma de texto } \\
\text { corrido, no item acervo em forma de } \\
\text { tabela abrindo nova janela e no item } \\
\text { SBPSC é apresentado em tabelas que } \\
\text { mostram o conteúdo ao clicar no link }\end{array}$ & $\begin{array}{l}\text { No item } \\
\text { serviços, } \\
\text { acervo e } \\
\text { SBPSC }\end{array}$ & 3 & $\begin{array}{l}\text { Padronizar todas as } \\
\text { listagens de itens } \\
\text { (links) em forma de } \\
\text { tabela que } \\
\text { mostram o } \\
\text { conteúdo ao ser } \\
\text { clicado no link }\end{array}$ \\
\hline $\begin{array}{l}\text { Visibilidade do } \\
\text { estado atual do } \\
\text { sistema }\end{array}$ & $\begin{array}{l}\text { Não é apresentado nenhum tipo de } \\
\text { mostrador na página quando a } \\
\text { página está carregando }\end{array}$ & $\begin{array}{l}\text { Em todas } \\
\text { as páginas }\end{array}$ & 0 & $\begin{array}{l}\text { Inserir um ícone } \\
\text { para indicar } \\
\text { quando a página } \\
\text { está carregando }\end{array}$ \\
\hline
\end{tabular}

Fonte: Elaborado pela autora.

Foram constatados no site 2 problemas de usabilidade com grau de gravidade 3, um que viola a heurística de "consistência e padrões" e outro que viola o "reconhecimento e não memorização" ambos os itens foram caracterizados como problema com alta prioridade de correção, pois dificultam a encontrabilidade das informações.

Dois problemas encontrados na análise foram caracterizados como de gravidade 2, um relacionado à heurística de "controle e liberdade do usuário" e outro de "consistência e padrões". Estes itens foram classificados como pequeno problema com baixa prioridade de correção, pois não prejudicam diretamente a utilização do sistema. No item de controle e liberdade do usuário, é possível voltar clicando no menu na página que deseja e no item consistência e padrões, a utilização da palavra serviços em dois contextos é confusa, mas não afeta o entendimento do conteúdo.

Foi identificado uma violação de heurística de "visibilidade atual do sistema do sistema" pois não existe indicação de carregamento da página, no entanto este foi considerado um problema de gravidade 0 , não sendo encarado necessariamente como um problema de usabilidade, pois não afeta a experiência de utilização e a finalidade do site, que contém páginas leves e carregamento rápido. 
Para uma observação mais profunda da experiência ao visitar o site da BPSC, foi realizada a análise heurística do site Sábio, utilizado para consulta ao acervo. Nesta etapa foram verificadas as páginas de Informações e Consulta ao acervo, não estão incluídas na análise as páginas do usuário. O resultado da avaliação pode ser observado no quadro 2 .

Quadro 2 - Análise heurística do Site Sábio

\begin{tabular}{|c|c|c|c|c|}
\hline \multicolumn{5}{|c|}{ Site de consulta ao acervo } \\
\hline Heurística Violada & Erro & Local & Gravidade & Solução \\
\hline $\begin{array}{l}\text { Visibilidade do } \\
\text { estado atual do } \\
\text { sistema }\end{array}$ & $\begin{array}{l}\text { Ao clicar em } \\
\text { qualquer uma das } \\
\text { páginas, não fica } \\
\text { claro qual a } \\
\text { página está } \\
\text { selecionada e o } \\
\text { caminho até ela. }\end{array}$ & \begin{tabular}{|l|} 
Nas páginas de \\
informações não \\
existe nenhum \\
indicativo e nas \\
outras páginas não \\
é fácil de identificar
\end{tabular} & 2 & $\begin{array}{l}\text { Identificar em todas as páginas } \\
\text { qual a página está selecionada em } \\
\text { uma hierarquia diferente das } \\
\text { outras informações / manter no } \\
\text { menu selecionado ou em cor } \\
\text { diferente a página atual }\end{array}$ \\
\hline $\begin{array}{l}\text { Flexibilidade e } \\
\text { consistência de uso }\end{array}$ & $\begin{array}{l}\text { Existe apenas um } \\
\text { caminho para } \\
\text { qualquer ação } \\
\text { que se deseje } \\
\text { realizar no site. }\end{array}$ & $\begin{array}{l}\text { Em todas as } \\
\text { páginas }\end{array}$ & 4 & $\begin{array}{l}\text { Inserir mais de uma forma de } \\
\text { executar para cada página. } \\
\text { Exemplo. Inserir uma barra de } \\
\text { busca que fique disponível em } \\
\text { todas as páginas. Inserir uma logo } \\
\text { que redirecione para a home. Ter } \\
\text { um botão de login fixo em todas as } \\
\text { páginas }\end{array}$ \\
\hline $\begin{array}{l}\text { Consistência e } \\
\text { padrões }\end{array}$ & $\begin{array}{l}\text { Não existe um } \\
\text { padrão de } \\
\text { tipografia nas } \\
\text { páginas }\end{array}$ & $\begin{array}{l}\text { No item de } \\
\text { informações }\end{array}$ & 1 & $\begin{array}{l}\text { Utilizar o mesmo padrão } \\
\text { tipográfico e de cores do site da } \\
\text { biblioteca ou do site de busca }\end{array}$ \\
\hline $\begin{array}{l}\text { Projeto estético e } \\
\text { minimalista }\end{array}$ & $\begin{array}{l}\text { O site não possui } \\
\text { uma hierarquia } \\
\text { das funções, não } \\
\text { sendo possível } \\
\text { identificar qual o } \\
\text { objetivo do site e } \\
\text { sua função } \\
\text { principal }\end{array}$ & Em todo o site & 4 & $\begin{array}{l}\text { Criar uma hierarquia para as } \\
\text { informações definindo qual o } \\
\text { objetivo principal do site }\end{array}$ \\
\hline $\begin{array}{l}\text { Informações de } \\
\text { ajuda e } \\
\text { documentação }\end{array}$ & $\begin{array}{l}\text { Não existe } \\
\text { nenhum tipo de } \\
\text { ajuda }\end{array}$ & Em todo o site & 3 & $\begin{array}{l}\text { Criar um FAQ ou um manual de } \\
\text { utilização dos principais itens do } \\
\text { site }\end{array}$ \\
\hline
\end{tabular}

Fonte: Elaborado pela autora.

Foram pontuadas durante a observação cinco violações de heurísticas; duas delas afetam diretamente a utilização do site, e estão classificadas com gravidade 4, uma de "flexibilidade e consistência de uso" e outra relacionado ao "projeto estético e minimalista", nos dois pontos a utilização, e experiência ao utilizar o site são afetados, fazendo com que o usuário perca tempo pensando em 
como realizar a principal atividade do site de consulta ao acervo. A heurística de "Informações de ajuda e documentação" foi classificada como de gravidade 3, pois não existe nenhum tipo de ajuda ou documentação no site que facilite ou auxilie na sua utilização. Foi classificado com gravidade 2 o problema de "visibilidade do estado atual do sistema", pois é uma questão que auxilia na utilização do site, mas não prejudica diretamente a sua eficiência. Foi observado também uma violação de "consistência e padrões" dentro do menu, sendo considerado um problema estético, pois sua existência não prejudica a usabilidade do site.

\subsection{Análise com Usuários}

Para o teste com usuários, foi elaborada uma perona tendo como base os dados de usuários fornecidos pela BPSC. A persona desenvolvida, foi a Mariana, uma aluna de Ensino Médio, com 18 anos, que tem como objetivo estudar para o vestibular e utiliza, tanto o espaço quanto o acervo da biblioteca para isso. Baseado na persona foram convidados 5 alunos, com um nível avançado de conhecimento de internet, do terceiro ano de uma escola particular para realizar o teste de usabilidade no site da biblioteca.

Para execução do teste foi elaborado um roteiro com 4 tarefas a partir da análise heurística realizada, a fim de traçar um paralelo entre os problemas encontrados na análise heurística e a experiência de utilização do site por usuários. As tarefas selecionadas foram:

a) Entrar na página da biblioteca e encontrar a documentação necessária para realizar cadastro para empréstimo domiciliar;

b) Encontrar em que espaço do prédio da biblioteca ficam o Setor de Literatura e o Infanto Juvenil;

c) Descobrir o que é o Sistema de Bibliotecas Públicas de Santa Catarina;

d) Pesquisar quais os livros da autora Carolina Maria de Jesus estão disponíveis na biblioteca. 
Para avaliar a usabilidade do site foram utilizados os três objetivos citados na ISO 9241 -11 (INTERNATIONAL ORGANIZATION FOR STANDARDIZATION, 2018), eficiência, eficácia e satisfação. Para mensurar a eficiência do site foi utilizado o parâmetro de conclusão da tarefa, o usuário conclui - eficiente, o usuário não conclui, não tem eficiência. No critério eficácia foi estimado um tempo ideal de realização de cada tarefa e comparado com o tempo utilizado pelos usuários. Os tempos estimados para cada uma das tarefas foram: tarefa 1 - 28s; tarefa 2 - 20s; tarefa 3 - 9s; tarefa 4 - 20s.

O quadro 3 apresenta os resultados obtidos no teste dos critérios de eficiência e eficácia:

Quadro 3 - Teste de eficiência e eficácia do site da BPSC

\begin{tabular}{|c|c|c|c|c|c|c|c|c|}
\hline & \multicolumn{2}{|c|}{ Tarefa 1} & \multicolumn{2}{|c|}{ Tarefa 2} & \multicolumn{2}{|c|}{ Tarefa 3} & \multicolumn{2}{|c|}{ Tarefa 4} \\
\hline & Eficiência & Eficácia & Eficiência & Eficácia & Eficiência & Eficácia & Eficiência & Eficácia \\
\hline Usuário 1 & $\begin{array}{l}\text { não } \\
\text { realizou a } \\
\text { tarefa }\end{array}$ & $\begin{array}{l}\text { tentou } \\
\text { por } \\
1 \mathrm{~min} 50 \mathrm{~s}\end{array}$ & $\begin{array}{l}\text { realizou } \\
\text { a tarefa }\end{array}$ & $20 s$ & $\begin{array}{l}\text { realizou a } \\
\text { tarefa }\end{array}$ & $5 s$ & $\begin{array}{l}\text { realizou a } \\
\text { tarefa }\end{array}$ & $34 s$ \\
\hline Usuário 2 & $\begin{array}{l}\text { não } \\
\text { realizou a } \\
\text { tarefa }\end{array}$ & $\begin{array}{l}\text { tentou } \\
\text { por } \\
3 \mathrm{~min} 27 \mathrm{~s}\end{array}$ & $\begin{array}{l}\text { realizou } \\
\text { a tarefa }\end{array}$ & $10 \mathrm{~s}$ & $\begin{array}{l}\text { realizou a } \\
\text { tarefa }\end{array}$ & $19 \mathrm{~s}$ & $\begin{array}{l}\text { realizou a } \\
\text { tarefa }\end{array}$ & $02 \mathrm{~min} 46 \mathrm{~s}$ \\
\hline Usuário 3 & $\begin{array}{l}\text { não } \\
\text { realizou a } \\
\text { tarefa }\end{array}$ & $\begin{array}{l}\text { tentou } \\
\text { por } \\
4 \text { min33s }\end{array}$ & $\begin{array}{l}\text { realizou } \\
\text { a tarefa }\end{array}$ & $1 \mathrm{~min} 03 \mathrm{seg}$ & $\begin{array}{l}\text { realizou a } \\
\text { tarefa }\end{array}$ & $10 \mathrm{~s}$ & $\begin{array}{l}\text { realizou a } \\
\text { tarefa }\end{array}$ & $01 \mathrm{~min} 31 \mathrm{~s}$ \\
\hline Usuário 4 & $\begin{array}{l}\text { não } \\
\text { realizou a } \\
\text { tarefa }\end{array}$ & $\begin{array}{l}\text { tentou } \\
\text { por } \\
3 \mathrm{~min} 30 \mathrm{~s}\end{array}$ & $\begin{array}{l}\text { realizou } \\
\text { a tarefa }\end{array}$ & $5 s$ & $\begin{array}{l}\text { realizou a } \\
\text { tarefa }\end{array}$ & $4 \mathrm{~s}$ & \begin{tabular}{|l} 
não \\
realizou a \\
tarefa
\end{tabular} & $\begin{array}{l}\text { tentou por } \\
1 \mathrm{~min} 47 \mathrm{~s}\end{array}$ \\
\hline Usuário 5 & $\begin{array}{l}\text { não } \\
\text { realizou a } \\
\text { tarefa }\end{array}$ & $\begin{array}{l}\text { tentou } \\
\text { por } 3 \mathrm{~min}\end{array}$ & $\begin{array}{l}\text { realizou } \\
\text { a tarefa }\end{array}$ & $15 \mathrm{~s}$ & $\begin{array}{l}\text { realizou a } \\
\text { tarefa }\end{array}$ & $17 \mathrm{~s}$ & \begin{tabular}{|l} 
não \\
realizou a \\
tarefa
\end{tabular} & $01 \mathrm{~min} 30 \mathrm{~s}$ \\
\hline
\end{tabular}

Fonte: Elaborado pela autora.

Pode-se observar que a primeira tarefa - localizar a documentação necessária para cadastro na biblioteca, com tempo estimado de execução de $28 \mathrm{~s}$ não pode ser considerada nem eficiente e nem eficaz, pois nenhum dos usuários conseguiram realizar a tarefa e tentaram realizar por até 4 min33s. Já nas tarefas dois e três, encontrar onde ficam localizados no prédio da biblioteca os setores de literatura e infanto-juvenil (tempo estimado 20s) e descobrir o que é o Sistema de 
Bibliotecas Públicas (tempo estimado de 9s), considera-se que o site foi eficiente e eficaz, pois todos os usuários conseguiram realizar ambas as tarefas, na tarefa dois quatro deles realizaram a tarefa ou no tempo estimado ou em menos tempo. e na tarefa três, todos realizaram a tarefa em até 20s. Na tarefa de número quatro - localizar os livros da autora Carolina Maria de Jesus (tempo estimado 20s), o site pode ser avaliado como eficiente, pois quatro dos cinco usuários conseguiram finalizar a tarefa, no entanto não pode ser considerado eficaz, pois três dos usuários que realizaram a tarefa levaram de quatro a oito vezes mais que o tempo estimado para realizar a tarefa.

Em relação a estimativa de satisfação, foram registradas as reclamações, elogios, e comentários realizados pelos usuários. Em relação a primeira tarefa, os usuários mostraram-se insatisfeitos, pois não conseguiram realizar a tarefa, surgiram comentários como "poderia ser mais direto, tem que abrir várias abas pra achar as informações"; "o site tem muita informação, tu não sabe onde clicar" (sobre o site da FCC, onde estão localizadas as páginas da biblioteca); "as informações são muito gerais, abertas, você tem meio que adivinhar onde clicar". Já em relação as tarefas dois e três, os usuários ficaram satisfeitos com o site, não houveram reclamações e um dos usuários comentou "esse aqui ficou bom" em relação a estrutura do site para a segunda atividade proposta. Na quarta tarefa, apesar de o site ser considerado eficiente, os usuários não ficaram satisfeitos com o site, três dos pesquisados fizeram reclamações como: "não tem onde buscar aqui" (se referindo ao site da FCC) este usuário complementa ainda após localizar o catálogo "poderia ser mais direto", outro comentário registrado foi "este site é préhistórico e você clica na home e aparece uma imagem, sem nenhuma informação" (referindo-se ao site do catálogo de livros Sábio. O usuário que não localizou o catálogo buscou diretamente na opção de busca do site da FCC e comentou "no site não tem a opção de busca por livros". 
Projética, Londrina, v. 12, n. 1, p. 168-194, março 2021

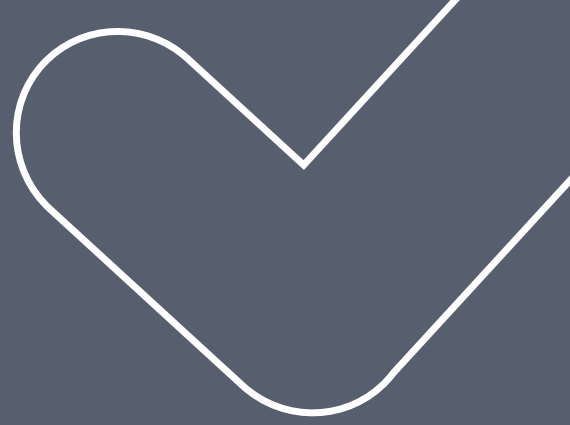

Em uma análise de usabilidade é importante levar em consideração além dos atributos apresentados na norma, os atributos de qualidade e afetivos, pois se as pessoas não puderem ou não utilizarem um recurso, ele pode não mais existir (NIELSEN; LORANGER, 2007). 


\subsection{Comparação da Análise Heurística e Teste com Usuários}

As quatro tarefas elaboradas para os usuários foram construídas a partir da análise heurística e buscavam verificar como os usuários se comportam diante das violações heurísticas encontradas. Partindo dos resultados obtidos no teste com os usuários pode ser traçado um paralelo entre estes e as heurísticas violadas.

A primeira tarefa apresentada, encontrar a documentação necessária para cadastro na biblioteca, tinha como objetivo verificar dois erros e violações heurísticas encontradas na análise, são elas: no item serviços, são apresentadas submenus clicáveis, porém não existe indicação ou diferenciação tipográfica de que são clicáveis e que existem mais itens em cada tópico, este erro foi considerado de gravidade três; o segundo erro avaliado foi a utilização da palavra serviços no menu e no submenu com significados diferentes, este erro foi avaliado com gravidade 2. Durante o teste com os usuários, observou-se que estas violações heurísticas afetaram diretamente a execução da tarefa, pois a mesma não foi realizada por nenhum dos participantes. Ao longo do teste, verificaram-se algumas observações relevantes, como, três dos participantes buscaram por uma opção de cadastro, tanto nas páginas da biblioteca, quanto no catálogo de livros. Também três alunos entraram no menu Sistema de Bibliotecas Públicas e encontraram a informação "cadastro eletrônico" e acreditaram ser o cadastro na biblioteca. Em relação ao menu em que se encontrava a informação, dois dos participantes não clicaram no menu serviços, por não considerar que as informações de cadastro poderiam estar dentro dele, os outros três que clicaram apenas um identificou que o submenu era clicável, no entanto, entrou na página das informações e não a localizou.

Outra heurística violada avaliada no teste de usabilidade foi a de consistência e padrões que apresentou como erro a utilização de três formas de apresentar submenus clicáveis. Para esta avaliação foram realizadas as tarefas um, dois e três, com estas tarefas o objetivo era identificar em qual dos três submenus 
apresentaria menos problemas de usabilidade. Percebeu-se que a forma utilizada dentro do menu Serviços é a que apresenta mais problemas de usabilidade, pois apenas um dos participantes percebeu que este submenu era clicável. Em relação aos outros dois menus, nenhum apresentou barreiras na execução das tarefas. Desta forma, fica a indicação de que todos os menus sejam padronizados de acordo com o menu Acervo ou Sistema de Bibliotecas Públicas.

Para verificar três erros encontrados, no catálogo de livros Sábio, durante a avaliação heurística, sendo eles: existe apenas um caminho de acesso para cada atividade do site; falta de hierarquia, não sendo possível identificar qual o objetivo do site e sua função principal função; não existir nenhum tipo de ajuda. Foi solicitada a execução da tarefa quatro, na qual o objetivo era identificar quais os livros disponíveis na biblioteca da autora Carolina Maria de Jesus. Esta tarefa, apenas um aluno não conseguiu executar, no entanto os outros quatro tiveram dificuldades de localizar dentro das páginas da biblioteca onde ficava a busca de livros. Três dos participantes inicialmente tentaram buscar os livros na pesquisa geral do site. Todos os usuários após entrarem no catálogo, pensavam um tempo, pois não havia campo de busca.

Uma observação que não havia sido pontuada na análise heurística é a de que três dos alunos após clicar no campo de busca realizaram a busca e não localizaram a autora, pois o sistema traz automaticamente a opção busca por título selecionada. Esta situação do sistema viola a heurística de Prevenção de erros ao já deixar um campo específico, sem dar a opção do usuário pesquisar em todos os campos.

Outro comportamento que não estava contemplados na análise heurística e que foi observado em três dos usuários: a dificuldade de identificar que as páginas da biblioteca estavam dentro do site da FCC e a falta de clareza para os mesmos de quando estavam na parte da biblioteca e quando já haviam saído, válido ressaltar 
que um dos usuários não localizou as páginas da Biblioteca Pública dentro da FCC e recorreu por pesquisar no Google "Biblioteca Pública de Santa Catarina", para localizar o site.

Já em relação aos itens avaliados na análise heurística, nos que apresentaram gravidade 0 (não é encarado necessariamente como um problema de usabilidade) e 1 (problema estético que não tem necessidade de ser corrigido, a menos que haja tempo e recurso disponível) observou-se que não prejudicaram a execução das tarefas e não foram mencionados pelos usuários durante a pesquisa. Outro erro verificado na análise heurística que não influenciou na execução das tarefas foi o em que clicar em qualquer uma das páginas, não fica claro qual a página está selecionada e o caminho até ela, no catálogo da biblioteca Sábio, considerado de gravidade 2 (pequeno problema com baixa prioridade de correção).

\section{CONCLUSÃO}

A interface é o elo de comunicação entre o computador e o usuário. É através das interfaces que são transmitidas as informações necessárias para que o usuário conheça e utilize seu sistema ou serviço. As bibliotecas como prestadoras de serviço que buscam atender e atingir o maior número de pessoas possíveis, precisam

dispor de interfaces que facilitem a localização de informações e sejam amigáveis aos usuários.

Durante a análise e teste com usuários foram identificados vários problemas de interface que influenciam diretamente as atividades principais de uma biblioteca, como por exemplo quando os participantes não conseguiram localizar como é realizado o cadastro para empréstimo domiciliar de materiais, ou ainda a dificuldade dos participantes em encontrar o local onde é realizada a busca de obras no acervo. 
A dificuldade de utilização de um site, faz com que usuários desistam de usufruir dos serviços disponibilizados por ele, pois causam frustração e o estabelecimento perde credibilidade. Para que isto não aconteça, é necessária a revisão dos sites e os testes com usuários. Na situação avaliada, propõe-se que inicialmente os principais erros e obstáculos encontrados pelos usuários sejam solucionados, por meio da revisão do site, buscando a consistência e padrões, tanto visual, quanto textual, que sejam reavaliadas as hierarquias, e melhor identificadas as opções clicáveis ou não.

Ao realizar a avaliação de usabilidade do site da Biblioteca Pública de Santa Catarina percebe-se que ainda há um caminho a ser trilhado na busca de uma interface que proporcione a melhor experiência a seus usuários. O trabalho de proporcionar a melhor experiência é constante, sendo sempre necessárias revisões de interface, de conteúdo e a realização de teste com usuários. 
Avaliação da usabilidade do site... Santa Catarina

CAPRI, D.; SILVA G. G. da

REFERÊNCIAS

1. BAX, Marcello Peixoto. As bibliotecas na Web e vice-versa. Perspectivas em Ciência da Informação, Belo Horizonte, v. 3, n. 1, p. 5-20, 1998.

2. BLATTMANN, Ursula; FRAGOSO, Graça Maria; VIAPIANA, Noeli. Bibliotecas públicas estaduais brasileiras na internet. Revista ACB, Florianópolis, SC, v. 11, n. 2, p. 315-332, dez. 2006. Disponível em: https://revista.acbsc.org.br/ racb/article/view/481/615. Acesso em: 16 abr. 2018.

3. BRINKLEY, Monica. The library web site in 1999: a virtual trip to the library. In: INTERNET LIBRARIAN \& LIBTECH INTERNATIONAL 99, 1999, London. Proceedings [...]. Medford, NJ: Information Today, 1999. p. 8-15.

4. COUTINHO, João José; PEREIRA, Manoel da Costa; CARDOZO, José Caetano. Resolução n. 373, 31 maio 1854, SC. Santa Catarina: Secretaria do Governo, 1854. Esta resolução estabelece uma Bibliotheca Pública instalada numa sala no edificio ocupado pela Assembléia Legislativa Provincial. Disponível em: https://repositorio.ufsc.br/handle/123456789/123460. Acesso em: 10 abr. 2018.

5. CYBIS, Walter de Abreu. Engenharia de usabilidade: uma abordagem ergonômica. Florianópolis: Labiutil-UFSC, 2003. Disponível em: http://www. labiutil.inf.ufsc.br/hiperdocumento/conteudo.html. Acesso em: 10 abr 2018.

6. CYBIS, Walter; BETIOL, Adriana Holtz; FAUST, Richard. Ergonomia e usabilidade: conhecimentos, métodos e aplicações. 3. ed. São Paulo: Novatec, 2015. 
Projética, Londrina, v. 12, n. 1, p. 168-194, março 2021

7. DIAS, Cláudia. Usabilidade na web: criando portais mais acessíveis. 2. ed. Rio de Janeiro: Alta books, 2007.

8. FONSECA, João José Saraiva da. Metodologia da pesquisa científica. Fortaleza: UEC, 2002.

9. GIL, Antônio Carlos. Como elaborar projetos de pesquisa. 4. ed. São Paulo: Atlas, 2007.

10. IBGE. População. Rio de Janeiro, RJ: IBGE, 2017. Disponível em: https://www. ibge.gov.br/estatisticas/sociais/populacao.html. Acesso em: 20 abr. 2018.

11. INSTITUTO PRÓ-LIVRO. Pesquisa retratos da leitura no Brasil. 4. ed. São Paulo: Instituto Pró-Livro, 2016. Disponível em: http://prolivro.org.br/home/. Acesso em: 10 abr. 2018.

12. INTERNATIONAL ORGANIZATION FOR STANDARDIZATION. ISO 9241-11:2018: ergonomics of human-system interaction - part 11: usability: definitions and concepts. Geneva, SW: ISO, 2018. Disponível em: https://www.iso.org/ standard/63500.html. Acesso em: 10 abr. 2018.

13. KOONTZ, Christie; GUBBIN, Barbara (ed.). Diretrizes da Ifla sobre os serviços da Biblioteca Pública. 2. ed. rev. Lisboa: IFLA, 2013. Disponível em: https:// www.ifla.org/files/assets/hq/publications/series/147-pt.pdf. Acesso em: 10 abr. 2018.

14. LAUREL, Brenda. The art of human-computer interface design. Boston: Addison-Wesley, 1990. 
15. NIELSEN, Jacob. Heuristic evaluation. In: NIELSEN Jacob, MACK, Robert L. (ed.). Usability inspection methods, heuristic evaluation. New York: John Wiley \& Sons, 1994.

16. NIELSEN, Jacob. Projetando websites. Rio de Janeiro: Elsevier, 2000a.

17. NIELSEN, Jacob; LORANGER, Hoa. Usabilidade na web projetando sites com qualidade. Rio de Janeiro: Elsevier, 2007.

18. NIELSEN, Jakob. Why you only need to test with 5 users. Fremont, CA: Nielsen Norman Group, 2000b. Disponível em: https://www.nngroup.com/articles/ why-you-only-need-to-test-with-5-users/. Acesso em: 10 abr. 2018.

19. OLIVEIRA, Zita Catarina Prates de. A biblioteca "fora do tempo": políticas governamentais de bibliotecas públicas no Brasil, 1937-1989. 1994. Tese (Doutorado em Ciência da Comunicação) - Universidade de São Paulo, SP, São Paulo, 1994.

20. ROCHA, Heloísa Vieira da; BARANAUSKAS, Maria Cecília. Design e avaliação de interfaces humano-computador. Campinas, SP: NIED/UNICAMP, 2003.

21. SALGADO, Denise Mancera; MODESTO, Fernando. Bibliotecas Públicas estaduais brasileiras e os catálogos online. In: IX EIC - ENCONTRO INTERNACIONAL DE CATALOGADORES, 9.; ENACAT - ENCONTRO NACIONAL DE CATALOGADORES, 2., Rio de janeiro, RJ. Anais eletrônicos [...]. Rio de Janeiro: Fundação Biblioteca Nacional, 2013. Disponível em: http://www. abinia.org/catalogadores/16-173-1-PB.pdf. Acesso em: 10 abr. 2018.

22. SANTA CATARINA. Lei n 11.074, de 11 de janeiro de 1999. Institui o Depósito Legal de Obras Impressas, junto à Biblioteca Pública do Estado de Santa 
Projética, Londrina, v. 12, n. 1, p. 168-194, março 2021

Catarina. Florianópolis, SC: Assembleia Legislativa, 1999. Disponível em: http://leis.alesc.sc.gov.br/html/1999/11074_1999_Lei.html. Acesso em: 10 abr. 2018.

23. SHARP, Helen; ROGERS, Yvonne; PREECE, Jenny. Interaction design: Beyond human-computer interaction. Miley, 2007.

24. SILVA, Bruno Santana da; BARBOSA, Simone Diniz Junqueira. Interação humano-computador: projetando a experiência perfeita. Rio de Janeiro: Campus, 2010.

25. SISTEMA NACIONAL DE BIBLIOTECAS PÚBLICAS - SNBP. Brasília, DF: Secretaria Especial da Cultura, 2018. Disponível em: http://snbp.cultura.gov. br/. Acesso em: 20 abr. 2018.

26. SUAIDEN, Emir J. Biblioteca pública brasileira: desempenho e perspectivas. São Paulo: Lisa, 1980. 